\title{
MÍDIA E DESIGN GRÁFICO NO PROCESSO DE COMUNICAC̣ÃO DO EVENTO CULTURAL FESTIVAL DE DANÇA DE JOINVILLE
}

Media and Graphic Design in the communication process of cultural event Festival de Dança de Joinville

\section{ZWIRTES, Amanda Machado I Doutoranda em Engenharia e Gestão do Conhecimento}

Universidade Federal de Santa Catarina

amandapiresmachado@yahoo.com.br

\section{SOUSA, Richard Perassi Luiz de I Doutor em Comunicação e Semiótica}

Universidade Federal de Santa Catarina

richard.perassi@uol.com.br

\section{Resumo}

Este artigo busca discutir a relevância das mídias e seus veículos no processo de comunicação do evento cultural Festival de Dança de Joinville. Partiu-se de uma pesquisa exploratória e documental, com coleta de dados e de materiais de divulgação (impressos e digitais) do evento (edições 2008-2012), e por meio de análise, descrição e interpretação buscou-se evidenciar o papel das mídias no processo de comunicação do Festival.

Palavras-chave: Mídia e veículos. Design gráfico. Comunicação. Evento cultural.

\section{Abstract}

This article discusses the relevance of media and their vehicles in the communication process of cultural event Festival de Dança de Joinville. Starting from an exploratory and documentary research, with data collection (printed and digital material) of the event (editions 2008-2012), and through analysis, description and interpretation of those, the authors intended to show the relevance of media in the event communication process.

Keywords: The Media. Graphic Design. Communication. Cultural event. 


\section{NTRODUC̣ÃO}

No mundo industrializado e globalizado da atualidade, a necessidade de divulgação de uma marca através de produtos gráficos é perceptível, visto o grande número de produtos similares que temos à disposição numa prateleira de supermercado, por exemplo. Como identificá-los, diferenciá-los? A divulgação se dá por meio de rótulos, embalagens ou, de maneira independente, como folhetos explicativos ou peças publicitárias. Todos estes elementos fazem parte da comunicação da marca como ação estratégica das empresas, dentro da área de Gestão da Marca ou Branding, que se ocupa do gerenciamento e controle de todas as formas de expressão da marca junto ao público (AAKER, 2007).

Esta necessidade de gerenciamento e controle das formas de expressão e comunicação de uma marca não diz respeito apenas às empresas que visam lucro. A preocupação em se comunicar com seus públicos tem abrangido outras organizações, como as instituições culturais. As organizações institucionais, públicas ou privadas, buscam promover ações que visam influenciar o comportamento do público, por meio da divulgação de campanhas nas áreas de Saúde, Educação, Esporte, Cidadania ou Cultura. Fazem isso para informar e promover atitudes ou ações públicas, decorrentes da divulgação e da participação em projetos ou eventos sociais assistenciais, educativos ou culturais, entre outros. Portanto, as instituições investem na comunicação e no relacionamento com seus públicos, constituindo-se como "marca" de promoção e desenvolvimento do bem estar social.

Como exemplo de instituição social que presta serviço na área da cultura, e que tem galgado êxito na construção de sua marca por meio do uso de diferentes mídias e produtos de design gráfico, temos o Festival de Dança de Joinville. Há mais de 30 anos é promovido o evento que, atualmente, é considerado o "maior festival de dança do mundo", com relação ao número de participantes (Guiness Book). São 11 dias de apresentações, que contam com a participação de grupos de dança profissionais e amadores. $O$ evento atende a diversos públicos distintos e, também, ao público em geral. Há programação para todos, incluindo atrações para crianças ou programação específica para profissionais e estudiosos da área de Dança.

A comunicação da marca Festival e suas atividades, ao longo dos anos, ocorrem por meio de inserções na mídia televisiva local e nacional, divulgação via anúncios em rádios, divulgação de produtos gráficos impressos próprios e divulgados por meio dos jornais impressos locais, uso de mídias externas (como busdoor e outdoor), por meio de páginas específicas relacionadas ao evento (oficiais ou não) e de notícias disponíveis em diversas páginas da Internet. Atualmente, há o reconhecimento internacional, que foi conquistado de maneira não planejada, como consequência da repercussão ampliada do evento, por meio 
da comunicação formal e informal e, especialmente, das informações postadas na rede.

Pretende-se discutir e apresentar, neste artigo, a relevância do uso das mídias e o papel do design gráfico no processo de comunicação do evento cultural Festival de Dança de Joinville ao longo da sua história. É pesquisa qualitativa, partindo de uma abordagem exploratória e documental, coletando dados, informações e documentos (oficiais e não oficiais) sobre o evento, mais especificamente compreendendo o período das edições de 2008-2012, onde, após a coleta, seleção e análise do material, estes foram descritos e interpretados com base na teoria apresentada.

\section{DESENVOLVIMENTO}

\section{O Design Gráfico no Processo de Comunicação da Marca}

A maioria das empresas apresentam seus produtos ou serviços para nós com o uso de uma marca gráfica como assinatura, que busca identificar, representar e diferenciar esta empresa/marca das demais concorrentes, num mercado de iguais. Para tal, esta empresa precisa se comunicar com o público, se fazer conhecer e expressar sua identidade, por meio de diferentes materiais de suporte a marca.

Neste contexto, o papel do design gráfico, por meio de seus produtos, é de informar e comunicar conceitos e ideias, contando, para isso, com o uso de diferentes tecnologias. Hollis (2005) comenta que são 03 as funções básicas do design gráfico: (1) identificar determinada coisa; (2) informar e instruir, indicando a relação de uma coisa com outra e (3) apresentar e promover, tornando a mensagem inesquecível para quem a recebe.

A atividade do designer gráfico gera diferentes produtos, que visam auxiliar nesse processo de comunicação e expressão da marca. Os produtos oriundos da ação do design gráfico são a marca gráfica, material de papelaria, criação de fontes, design editorial, criação de cartazes, anúncios para jornais e revistas, etiquetas, embalagens e rótulos de produtos, diagramas, sistemas visuais de orientação/sinalização, layout de exposições, displays de divulgação para feiras e eventos, manuais de identidade corporativa (Brandbook). Salientase que os produtos indicados e a forma da comunicação do conceito de marca devem estar previstos anteriormente com base no Branding da empresa.

Como toda peça de design gráfico nasce da necessidade de promover, comunicar algo, a ênfase não deve estar na peça física ou digital em si, já que são apenas meios, mas sim, na interação que provoca entre quem emite a mensagem (a empresa) e o receptor da comunicação (público alvo). Por isso, tão importante quanto elaborar esta mensagem é planejar o impacto que esta 
terá junto ao público, suas atitudes e seu comportamento. Frascara (2001) diz que o êxito de qualquer campanha comunicacional deve considerar o público a que se destina, assim como considerar a campanha como parte de todo um processo evolutivo da comunicação da empresa.

Os projetos gráficos, que têm como objetivo a comunicação de algo, são necessários porque atuam como suporte privilegiado para a comunicação organizacional, independente da classe da organização, compondo de maneira direta ou indireta a identidade corporativa. Gomez e Perassi (2007) dizem, inclusive, que as peças gráficas são fundamentais na apresentação da marca, explorando aspectos simbólicos, promovendo a lealdade do consumidor, criando vínculo emocional.

O uso dos produtos de design gráfico se faz pertinente a todos os tipos de organização, sejam aquelas que visam lucro ou com fins lucrativos, pois todas possuem seu público-alvo específico, assim como tem seus objetivos junto a esse público. Da mesma forma, estas organizações sociais também se colocam junto ao público como "marcas" promotoras de bem estar social, crescimento e desenvolvimento, onde cabem estratégias e meios específicos de comunicação a fim de se atingir os objetivos iniciais.

\section{O Papel das Mídias e dos Veículos de Comunicação}

Uma revista. Um jornal. Uma embalagem. Um cartaz. São exemplos de produtos de design gráfico com os quais temos contato diariamente, em diferentes ambientes e contextos. Estes produtos se apresentam e interagem conosco, expressando ideias, conceitos, transmitindo informações. Foram idealizados para informar, divulgar, comunicar alguma coisa, mas cada um deles, por meio de seus elementos e sinais, remete a diferentes associações, interpretações e significados. Também são expressos de formas diversas, materializados sobre variados suportes, se utilizando de diferentes mídias, canais de comunicação.

Os produtos gráficos de comunicação, sejam impressos ou digitais, são responsáveis não só por transmitir informações pertinentes à marca, mas também por ajudar a comunicar ideias sobre a empresa em questão no que concerne a sua identidade e imagem. Hoje, com as tecnologias disponíveis, o usual é uma empresa se utilizar de diferentes mídias e veículos, que se complementam, no processo de comunicação de uma mesma marca.

Dentro da área de Design, segundo a Associação dos Designers Gráficos (ABC DA ADG, 1998), mídia é o termo utilizado para designar os veículos de comunicação, no seu conjunto ou em particular. Já o termo veículo é conceituado 
como qualquer instrumento de comunicação que leve uma mensagem para o consumidor, como por exemplo, jornal, revista, emissora de TV, rádio.

Com relação a esta pesquisa, tendo como foco a participação dos produtos de design gráfico impressos e digitais na comunicação da marca cultural Festival de Dança de Joinville, usa-se o termo mídia de forma mais ampla, como o Dicionário da ADG (ABC DA ADG, 1998), compreendendo os canais de comunicação influenciados pelas tecnologias para a transmissão de informação e, dentro destas mídias, são utilizados os veículos que as configuram (com características comuns, que os identificam enquanto segmento), dando suporte para que a informação seja expressa, perceptível e materializada.

Pertencentes à categoria de mídia impressa, estão os veículos de comunicação e informação que se referem aos materiais impressos bidimensionais (jornais, revistas, informativos, anuários, catálogos, folhetos, livretos, cartazes, mala diretas, folders, encartes, etc.). Já a mídia digital compreende os veículos e suportes de comunicação baseados em tecnologia digital, que permite a distribuição da informação de forma digital e que normalmente utiliza como meio um computador ou equipamento digital para criar um projeto que tem como suporte a rede, a internet.

Para Charaudeau (2007), a importância dos veículos e das mídias de comunicação está no papel social que estes suportes tecnológicos têm de difundir e divulgar as informações relativas aos acontecimentos do espaço público. Com relação ao Festival, as mídias e seus veículos são utilizados como fonte de promoção do evento, mas, também de informação a todos os efetivamente interessados e àqueles que poderão vir a se interessar pelo Festival.

Dentro do processo de comunicação, antes disso, de elaboração e da informação, o design se beneficia das possibilidades das diferentes mídias existentes para transmitir a informação. A mídia impressa e a mídia digital podem se completar, sendo utilizadas dentro de suas possibilidades, divulgando informação ao público de forma local e mais abrangente, numa amplitude de comunicação, mas buscando manter sua identidade enquanto organização ou produto. A mídia digital já tem feito parte do planejamento, da Gestão de Marca das organizações, por contribuir como canal de relacionamento entre a marca e seu público de forma mais abrangente, sendo papel do designer a construção e manutenção da identidade visual entre essas diferentes mídias.

\section{METODOLOGIA}

Esta pesquisa se caracteriza como qualitativa, por se basear na 
interpretação dos fenômenos e na atribuição de significados aos dados coletados (SILVA; MENEZES, 2005), a partir de uma análise construída por meio das interpretações feitas pelo próprio pesquisador. Ou seja, por meio da coleta e análise de dados e documentos referentes ao Festival, pretende-se identificar o papel das mídias e dos veículos de comunicação no processo de comunicação do evento.

Do ponto de vista de sua abordagem, esta pesquisa se caracterizou como exploratória e descritiva. A pesquisa iniciou numa busca por informações gerais a respeito do evento cultural Festival de Dança de Joinville. Posteriormente, foram coletados dados utilizados para o desenvolvimento da pesquisa (documentos textuais e visuais, informações, materiais gráficos impressos e digitais pertinentes ao evento, compreendendo as edições de 2008-2012) por meio de documentação indireta (através de pesquisa documental e bibliográfica), conforme Marconi e Lakatos (2003).

Por meio da coleta, seleção, descrição e interpretação deste material, buscou-se chegar a responder aos objetivos que nortearam a pesquisa, de identificar a relevância das mídias e dos veículos de comunicação no processo de comunicação do evento Festival de Dança de Joinville.

\section{Pesquisa Exploratória e Documental sobre o evento Cultural Festival de Dança de Joinville}

O evento Festival de Dança de Joinville, que ocorre anualmente, em 2015 completará sua trigésima segunda edição. Ao longo dos anos, o evento integrouse de tal forma ao contexto a cidade que o abriga, que esta é considerada não mais apenas a "cidades das flores" ou "cidade dos príncipes", mas também como "capital nacional da dança (desde 1987)", numa clara alusão ao Festival, que já se atrelou a cultura da cidade e a vida desta.

Em seus mais de 30 anos de existência (iniciando suas atividades em 1983, na cidade de Joinville/Santa Catarina), o Festival se consolidou pelo profissionalismo apresentado, pela pluralidade dos participantes e por sua tradição. São 11 dias de apresentações, onde o evento atrai diferentes públicos, já que abriga diversos eventos menores que fazem parte do grande evento Festival de Dança, cada qual com seus objetivos e com seu público-alvo, com seus interesses específicos. Há quem venha para concorrer na Mostra Competitiva adulta, apresentar-se no Meia Ponta (voltado para o público infantil) ou Palcos Abertos nas praças, bairros, shoppings e fábricas ou com foco voltado a atividade didática, como a realização de cursos e oficinas com fins de aperfeiçoamento profissional, workshops gratuitos para os coreógrafos inscritos no evento, seminários de dança, projetos comunitários, palestras, 
debates, entre outras ações.

Mantido com o apoio de patrocinadores e promovido pelo Instituto Festival de Dança de Joinville, o evento reúne mais de seis mil participantes diretos e atrai público superior a 200 mil pessoas numa média de 170 horas de espetáculos, o que inclusive lhe valeu a citação como o Maior Festival de Dança do Mundo no Guinness Book de 2005. É o maior concurso de estudantes de dança da América Latina, reconhecido pela grandiosidade, organização e qualidade técnica (FESTIVAL DE DANÇA DE JOINVILLE, 2012).

Para o desenvolvimento desta pesquisa, foram coletados materiais de comunicação e divulgação - impressos e digitais - do Festival de Dança, compreendendo os anos de 2008-2012, assim como uma busca histórica pelos materiais que poderiam ter sido utilizados em anos anteriores, para a construção de uma linha do tempo. A escolha deste intervalo de tempo se deu porque foi neste período em que houve o reestabelecimento de uma nova identidade visual para o evento, que sinalizou um marco importante na história deste.

Figura 1 - Evolução das marcas do Festival (I-1987, II-2004 e III-2009-atual).

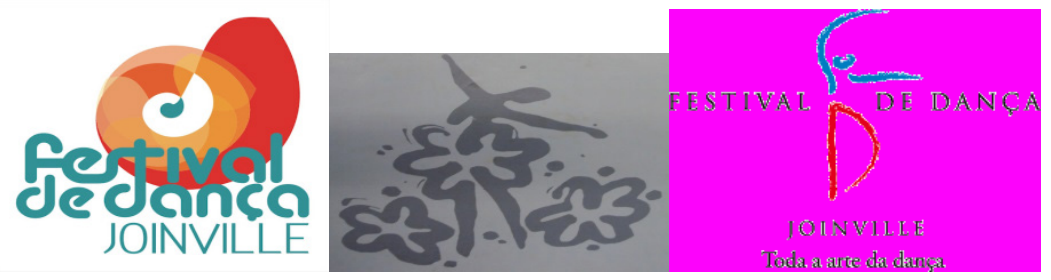

Fonte: Acervo Histórico de Joinville e Portal Institucional do Festival de Dança (2012)

Parte do material foi fornecido pelo próprio instituto organizador (o Instituto Festival de Dança de Joinville), que dispunha do material, fornecendo informações e amostras dos produtos gráficos impressos utilizados para comunicação no período de 2008-2012.

O material impresso coletado foi composto por cerca de 50 peças gráficas diferentes. Dessas 45,8 são relacionadas à edição de 2008, 09 relacionadas à edição de 2009, 10 relacionadas à edição 2010 e 7 relacionadas à edição 2011. As 11 restantes são relacionadas a edições anteriores (2006, 2007). Nesta contagem não estão sendo considerados os cartazes, cujas amostras físicas não foram conseguidas, apenas fotografias de amostras. 
Figura 2 - Painel com materiais impressos de divulgação do Festival (2011)

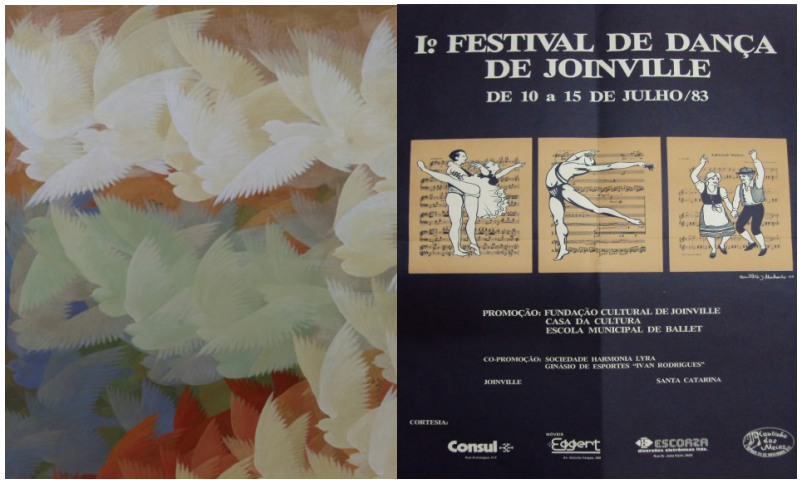

Fonte: Festival de Dança de Joinville (2012)

Das edições do Festival até 2012, foram conseguidas imagens de 23 cartazes, onde 02 dessas foram encontradas e retiradas diretamente de sites da internet, com notícias sobre o evento. Durante todas as edições do Festival, o cartaz se fez presente como um dos primeiros veículos de divulgação utilizado, mas, hoje, seu uso está mais para documento de registro, como um referencial simbólico do evento.

Figura 3 - Cartazes de divulgação do Festival (1983 e 2011)
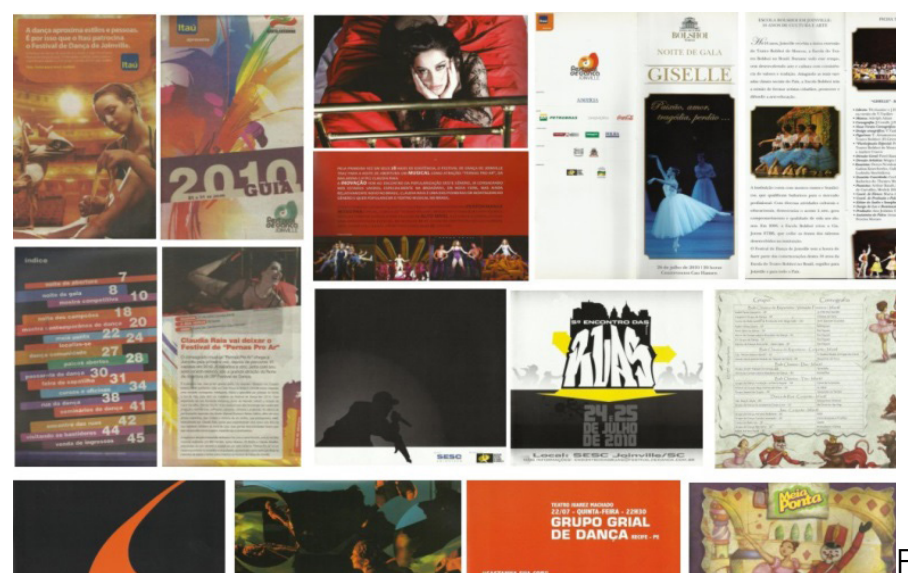

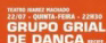

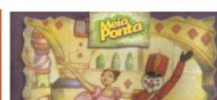

Acervo Histórico de Joinville e Portal Institucional do Festival (2012)

Foram obtidas informações relevantes também no Acervo Histórico da cidade de Joinville, com notícias e divulgações referentes ao Festival - seja como notícias ou como encartes especiais - em jornais impressos locais, assim como também amostras dos cartazes impressos utilizados na maioria das suas edições, e principalmente informações das edições mais antigas.

Por meio da rede internet, tivemos acesso a informações oficias (via site institucional) e não oficiais, divulgadas por outras fontes, repercutindo o evento de alguma forma e contribuindo para sua abrangência e conhecimento. Desde o ano 2000, o evento dispõe de um site institucional na internet com informações

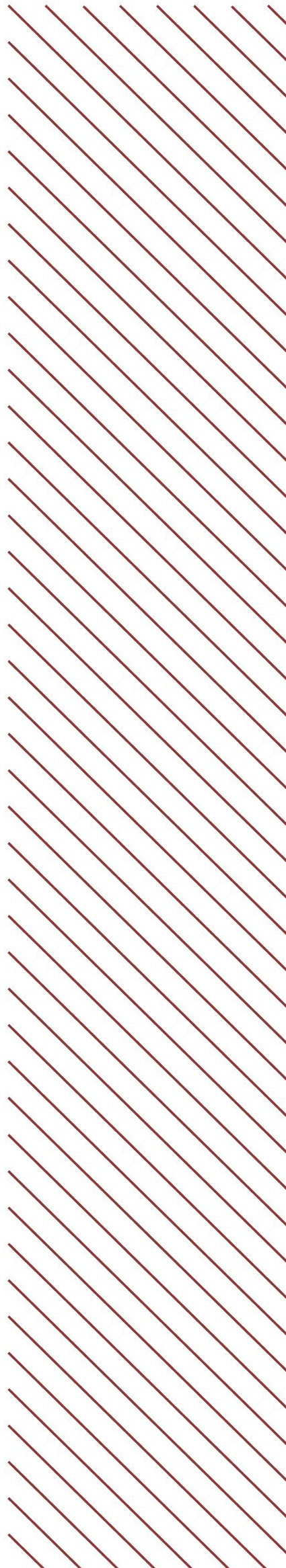


sobre a edição atual e registros das edições passadas.

Figura 4 - Páginas do site institucional (2004 e 2011)

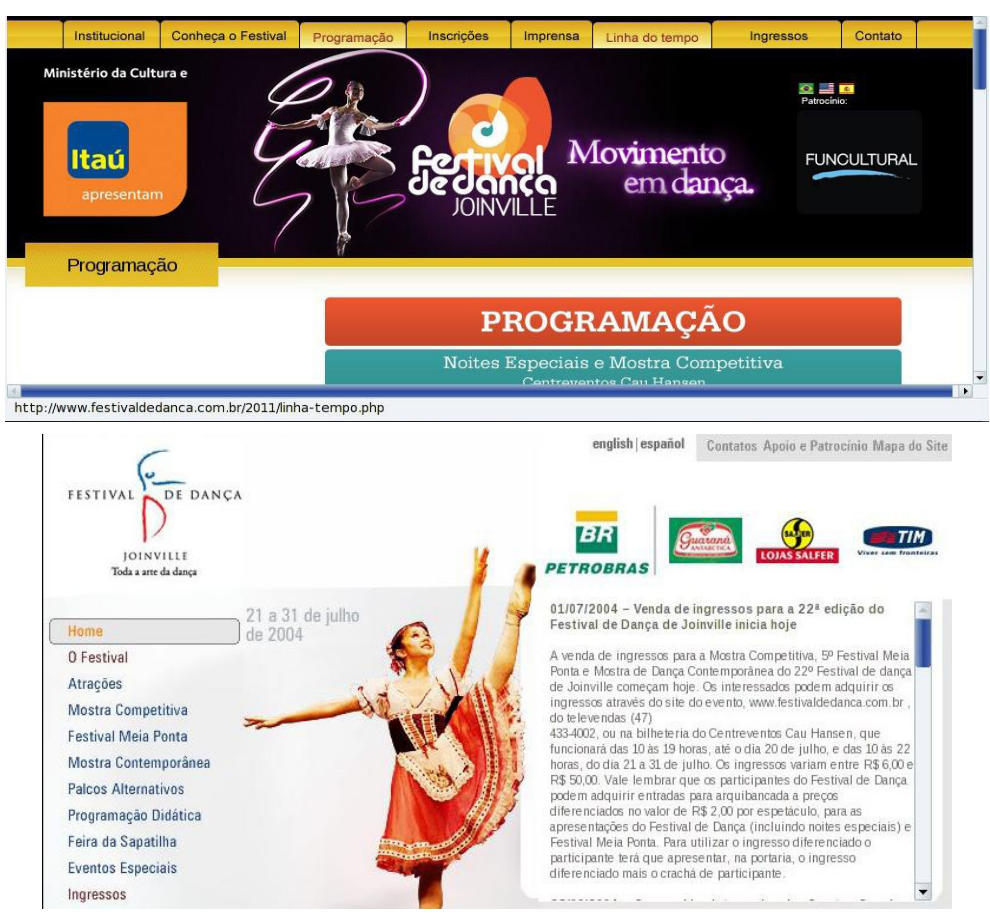

Fonte: Portal Institucional do Festival (2012)

Desde sua criação o site evoluiu, apresentando mudanças positivas com relação ao conteúdo, ao layout e à usabilidade, apresentando um layout mais constante a partir do ano de 2011. Através das informações disponíveis no site é possível identificar, conforme já comentado, a substituição do símbolo gráfico que representa o evento, pois a partir de 2009 é apresentada uma marca gráfica diferente da que era divulgada entre os anos de 2004 e 2008.

\section{DISCUSSÃO E RESULTADOS}

Ao longo da história do Festival de Dança de Joinville, se fizeram presentes o uso de diferentes mídias e veículos de comunicação sobre o evento. A divulgação via mídia televisiva e via rádio local, amplamente utilizadas no início de sua história, ainda persistem, mas com menor abrangência e dividindo espaço com outros tipos de mídia, advindas das novas tecnologias surgidas, de maior alcance e menor custo, como a mídia digital via rede Internet.

A mídia gráfica impressa teve e ainda tem um papel relevante na comunicação e fortalecimento da identidade do evento Festival de Dança de Joinville. Desde o princípio, quando este ainda precisava se apresentar, mostrar quem era, quais seus propósitos e objetivos, até a atualidade, contribuindo para a consolidação de sua imagem e reconhecimento. Hoje, o evento já está 
consolidado e com conhecimento prévio já estabelecido, não necessitando mais que este seja apresentado ou explicado. Neste sentido, o papel das mídias e veículos de comunicação do Festival se ampliou, de veículos de comunicação e informação pertinentes ao/sobre evento à construtores do universo simbólico que permeia e faz parte do que é o Festival.

Com o passar dos anos, com o crescimento e abrangência do evento, em termos de estrutura (criação do Instituto Festival de Dança), ampliação de atividades e de público alvo, este também passou a se utilizar da mídia digital via rede Internet, com a criação de um site institucional de divulgação (ano 2000). Alterações e modificações no layout do site foram sendo feitas, ocorrendo paralelamente à criação e modificações na marca gráfica, que representas e identifica graficamente o evento, e, neste mesmo contexto, o reconhecimento pelo Guiness Book do Festival como maior evento de dança do mundo, em número de participantes.

Os exemplos conseguidos de produtos gráficos impressos, das edições de 2008-2012, nos mostram que estes não só comunicavam informações pertinentes ao evento (como data, local, apresentações, atividades, etc.), mas sim, expressavam as modificações internas neste enquanto estrutura e conceito, reveladas nos diferentes materiais, na forma e composição da mensagem foi dando forma ao evento e expressando-o como este é reconhecido atualmente.

O papel fundamental de qualquer material de design gráfico é comunicar e informar, e os materiais utilizados pelo evento cumprem essa função. Mas toda a elaboração do discurso deles propõe algo mais, visto que o foco não recai na informação a ser transmitida em si, mas em como esta será expressa, em que contexto, buscando reproduzir um pouco do universo do qual o Festival faz parte e da identidade das pessoas envolvidas e interessadas pelo evento. Neste sentido, é inegável o papel das mídias e dos veículos de comunicação no processo de comunicação do evento Festival, ao contribuir para o fortalecimento e solidificação da imagem que o Festival tem na atualidade, de identidade diversa (diversidade).

\section{CONSIDERAC̣ÕES FINAIS}

O Festival de Dança de Joinville é um exemplo de evento cultural organizado por uma instituição social que se utilizou, desde o princípio de sua história, do uso de diferentes mídias e veículos de comunicação, ainda que de forma instintiva e sem planejamento, e de como estes, através dos tempos, foram usados para expressar as transformações pelas quais o evento passou, contribuindo para o fortalecimento de sua imagem na atualidade. Isto pode ser identificado ao se olhar uma ou outra peça gráfica produzida no período que 
compreende os últimos 05 anos, onde as transformações pelas quais o evento estava passando (em termos como estrutura, abrangência e identidade) estão expressas de forma perceptível na estruturação do discurso que compõe as mensagens visuais, comunicadas por meio de diferentes veículos e mídias.

As mídias e os veículos de comunicação são indispensáveis a qualquer marca da atualidade, no processo de comunicação e expressão de sua identidade. Por meio de sites institucionais digitais, propagandas televisivas, jornais, revistas e tantos outros meios, é possível ajudar a construir uma imagem de marca forte frente ao público a que se destina e se diferenciar dos concorrentes. Todos os elementos que compõe cada uma das mensagens veiculadas por estes diferentes canais falam, comunicam e expressam conceitos acerca da marca, empresa ou instituição a que representam.

O uso de diferentes mídias comunicando uma mesma instituição, por exemplo, deve buscar a coesão e unidade entre os diferentes materiais, mas, comunicando uma mesma marca. Por isso se faz relevante uma Gestão de Marca, que preveja como devem ser expressos elementos que dão conta da sua identidade, em diferentes plataformas, mas comunicando uma mesma ideia (identidade).

As instituições ou organizações não governamentais na atualidade também estão se utilizando do uso de mídias para comunicar suas ideias, seus projetos, e se fazerem conhecidas e reconhecíveis junto ao seu público. Mesmo que estas instituições não tenham, como as demais organizações, o objetivo principal visando lucro, também tem seus públicos de interesse, seus projetos a divulgar, logo, podem fazer uso das mídias e dos veículos, dentro de uma gestão, para auxiliar na comunicação.

Neste contexto salienta-se o papel relevante e social do design gráfico na construção e formulação dos elementos que compõe a mensagem visual identificando e comunicando eventos e tantos outros projetos desenvolvidos pelas diversas instituições sociais que temos em nosso país, num processo benéfico para a instituição que detém o evento e para a cidade que o sedia (na ampliação de geração de renda e empregos). É um desafio às instituições sociais, que desenvolvem projetos que beneficiam tantas pessoas, seja por meio de acesso a cultura, saúde, esportes, e que pouco se utilizam por desconhecerem (ou imaginarem ser algo financeiramente inacessível) ou pouco sabem dos benefícios da comunicação e uso de mídias variadas para a expressão e transmissão de seus projetos, ideias e conceitos, e, consequentemente, do conhecimento de sua marca.

O Festival de Dança é um exemplo de evento que, enquanto marca, se 
beneficiou do uso das mídias e dos veículos de comunicação para se fazer conhecer e, hoje, é reconhecido internacionalmente. Os produtos gráficos do evento, mais que informar sobre ele, expressam a identidade do Festival, e tendo sido de suma importância para a comunicação e expressão do evento, em seu processo de amadurecimento e abrangência.

Hoje, veículos que não são mais utilizados com a função prioritária de informar, como é o caso dos cartazes, mas ainda se fazem presentes na história do Festival, ajudando a construir o universo simbólico que o permeia e que faz o Festival ser o que é, ao longo desses mais de 30 anos. Paralelamente, a mídia digital ofereceu ao evento um dinamismo e acesso além das barreiras locais, contribuindo para sua expansão e conhecimento. Ambas as mídias tiveram (tem) o seu papel e sua relevância para a história do Festival.

\section{REFERÊNCIAS}

AAKER, David Aaker. Administração estratégica de mercado. Porto Alegre: Bookman, 2007.

\section{ABC DA ADG: Glossário de termos e verbetes utilizados em Design}

Gráfico. São Paulo: Associação dos Designers Gráficos, 1998.

CHARAUDEAU, Patrick. Discurso das mídias. São Paulo: Contexto, 2007.

FESTIVAL DE DANÇA DE JOINVILLE. Portal Institucional, 2012. Disponível em: <http://www.ifdj.com.br/site/>. Acesso em: 10 out. 2014.

FRASCARA, Jorge. Diseño gráfico para la gente: comunicaciones de masa y cambio social. Buenos Aires: Ediciones Infinito, 2001.

GOMEZ, Luiz Salomão Ribas; PERASSI, Melissa Q. Branding e design gráfico. In: ENCONTRO INTERNACIONAL DA UNIDCOM/IADE, 3., 2007, Lisboa. Anais... Lisboa: IADE, 2007. p. 43-51.

HOLLIS, Richard. Design gráfico: uma historia concisa. São Paulo: Martins Fontes, 2005.

MARCONI, Marina de Andrade.; LAKATOS, Eva Maria. Fundamentos da metodologia científica. São Paulo, Atlas: 2003.

SILVA, Edna Lúcia; MENEZES, Estera Muszkat. Metodologia da Pesquisa e elaboração de dissertação. Florianópolis: Universidade Federal de Santa Catarina, 2005. 